\title{
Hong Kong Chinese school children with elevated urine melamine levels: A prospective follow up study
}

\author{
Alice PS Kong ${ }^{1,2}$, Kai-Chow Choi ${ }^{3 *}$, Chung Shun Ho ${ }^{4}$, Michael HM Chan ${ }^{4}$, Chun Kwok Wong ${ }^{4}$, Eric KH Liu ${ }^{5}$,
} Winnie CW Chu', Viola CY Chow ${ }^{6}$, Joseph TF Lau ${ }^{7}$ and Juliana CN Chan ${ }^{1,2,8}$

\begin{abstract}
Background: In 2008, the outbreak of kidney stones in children fed by melamine-tainted milk products in Mainland China has caused major public concern of food safety. We identified Hong Kong school children with elevated urine melamine level from a community-based school survey in 2007-08 and reviewed their clinical status in 2009.
\end{abstract}

Methods: In 2007-08, 2119 school children participated in a primary and secondary school survey in Hong Kong using a cluster sampling method. Urine aliquots from 502 subjects were assayed for melamine level. High urine melamine level was defined as urine melamine/creatinine ratio $>7.1 \mu \mathrm{g} / \mathrm{mmol}$. Subjects with high urine melamine level were invited for clinical evaluation in 2009 including urinalysis and ultrasound imaging of the urinary system.

Results: The age range of this subcohort was 6 - 20 years with 67\% girls (335 female and 167 male subjects). The spot urine melamine/creatinine ratio of the 502 urine aliquots ranged from undetectable to $1467 \mu \mathrm{g} / \mathrm{mmol}$ (median $0.8 \mu \mathrm{g} / \mathrm{mmol}$ ). Of these, 213 subjects had undetectable level (42\%). We invited 47 (9\%) subjects with high urine melamine level for re-evaluation and one subject declined. The median duration of follow-up was 23.5 months (interquartile range: 19.8 - 30.6 months). None of the 46 subjects (28\% boys, mean age $13.9 \pm 2.9$ years) had any abnormality detected on ultrasound study of the urinary system. All subjects had stable renal function with a median urine albumin-creatinine ratio of $0.70 \mathrm{mg} / \mathrm{mmol}$ (interquartile range: $0.00-2.55 \mathrm{mg} / \mathrm{mmol}$ ).

Conclusions: Hong Kong Chinese school children with high urine melamine levels appeared to have benign clinical course in the short term although a long term follow-up study is advisable in those with persistently high urine melamine level.

\section{Background}

Since the outbreak of kidney stones in children fed with melamine-tainted milk products in Mainland China in early September 2008, the public concern of food safety has escalated to a new height [1]. Hong Kong is closely connected to Mainland China. Food supplies, immigrants and travellers from Mainland China are possible reasons for Hong Kong children to be affected by melamine-tainted food products. Moreover, melamine is widely used in plastics, dishware, laminates, glues and

\footnotetext{
* Correspondence: kchoi@cuhk.edu.hk

${ }^{3}$ The Nethersole School of Nursing, The Chinese University of Hong Kong, Shatin, Hong Kong SAR, China

Full list of author information is available at the end of the article
}

toy coating. Therefore, melamine is a potential food contaminant with public health hazards. Sporadic cases of melamine incident had been reported in Hong Kong and the incidence of renal involvement (echogenic renal foci) has been reported to range from $0.03 \%$ to $0.6 \%$ depending on selection criteria and methods of evaluation [2-4]. To date, there is no population data on melamine exposure and their possible health consequences.

In 2007-08, we conducted a territory wide survey to examine the prevalence of metabolic syndrome in Hong Kong youth. Using archived urine samples, we assayed the urine melamine levels in a subcohort and evaluated their clinical status after 2 years. We also explored the

\section{Biomed Central}

(c) 2011 Kong et al; licensee BioMed Central Ltd. This is an Open Access article distributed under the terms of the Creative Commons Attribution License (http://creativecommons.org/licenses/by/2.0), which permits unrestricted use, distribution, and reproduction in any medium, provided the original work is properly cited. 
correlation between urinary melamine level and daily milk consumption in these school children.

\section{Methods \\ Participants}

Stored urine aliquots were collected from a territorywide, population recruited cohort surveyed in 2007-08. The subjects and methodology have been described previously [5]. In brief, 2119 Hong Kong Chinese school children aged 6 - 20 years from 5 primary schools (804) and 6 secondary schools (1315) were randomly selected from all schools in Hong Kong using a cluster sampling method [5]. Informed written consents were sought from both the participants and their parents or guardians. The study was approved by the Joint Chinese University of Hong Kong-New Territories East Cluster Clinical Research Ethics Committee (CREC, Ref. No.: CRE-2006.136-T and CRE-2009.272). All participants were enquired about their habit of milk consumption using the question, "Are you drinking more than one cup of milk per day?" in a validated one-minute dietary questionnaire [6]. Spot morning urine specimens were collected from all agreeable participants during the field study for measurement of albumin-creatinine ratio (ACR). Albuminuria was defined as ACR $>3.5 \mathrm{mg} /$ mmol [7]. A total of 502 urine aliquots were assayed for melamine level (funding was available for 502 melamine assays only). High urine melamine level was defined as urine melamine/creatinine ratio $>7.1 \mu \mathrm{g} / \mathrm{mmol}$ [8]. Subjects with high urine melamine level were invited for clinical evaluation in 2009 including urinalysis and ultrasound imaging of the urinary system. Renal ultrasonography was performed by an experienced radiographer using the Philips ATL HDI5000 ultrasound machine. During ultrasound evaluations, both kidneys were carefully evaluated for the presence of renal stones, hydronephrosis or related renal scarring.

\section{Laboratory assays}

Urine melamine was measured by a liquid chromatography tandem mass spectrometry (LC-MS/MS) method. Twenty $\mu \mathrm{l}$ of urine sample was added to $200 \mu \mathrm{l}$ acetonitrile $(\mathrm{ACN})$ containing $10 \mathrm{ppb}$ stable isotope labeled melamine internal standard $\left({ }^{13} \mathrm{C}_{3},{ }^{15} \mathrm{~N}_{3}\right.$-melamine, Cambridge Isotope Laboratories, Andover, MA, USA). The solution was vortex mixed before centrifugation at $16,000 \mathrm{~g}$ for $5 \mathrm{~min}$ and the clear supernatant was transferred to a sample vial, ready for LCTMS. The measurement was performed on a UPLC ${ }^{\circledR}$ Waters Xevo TQ System (Waters, Milford, MA, USA). Calibrators, 10 $1000 \mu \mathrm{g} / \mathrm{l}$, were prepared by spiking appropriate amounts of melamine into a negative pooled urine sample. Five $\mu \mathrm{l}$ of calibrators/extracted melamine samples was injected into an ACQUITY UPLC ${ }^{\circledR}$ BEH HILIC column $(2.1 \times 150 \mathrm{~mm}, 1.7 \mu \mathrm{m})$ which was kept at $45^{\circ}$ C. Weak and strong wash solutions for UPLC $^{\circledR}$ were $\mathrm{ACN}$ and water, respectively. We used $50 \% \mathrm{ACN}$ in water as the seal wash solution. Melamine and the internal standard were separated from matrix interference by a gradient program using mobile phase solutions of 10 $\mathrm{mM}$ ammonium acetate in water and $10 \mathrm{mM}$ ammonium acetate in $97 \% \mathrm{ACN}$ in water at a flow rate of 500 $\mu \mathrm{l} / \mathrm{min}$. For the mass analyzer, capillary voltage was optimized at $3.9 \mathrm{KV}$; cone voltage at $40 \mathrm{~V}$ and collision energy at $24 \mathrm{~V}$. The source and desolvation temperatures were at $150^{\circ} \mathrm{C}$ and $500^{\circ} \mathrm{C}$, respectively. Positive electrospray ionization tandem MS analyses were performed using $m / z 127-85$ and 127-68 as quantitative and qualitative MRMs for melamine, respectively; and $m / z 133-89$ as the MRM for the internal standard. The dwell time for each MRM was $50 \mathrm{msec}$. Both melamine and the internal standard eluted at around $3.5 \mathrm{~min}$. Additional mobile phase gradient programming was used to remove matrix interference and recondition the column for the next analysis. Injection to injection time was $6 \mathrm{~min}$. Quantitation was performed by the TargetLynx Manager of the Waters MassLynx 4.1 software. The limit of quantitation was $5 \mu \mathrm{g} / \mathrm{l}$ and the linearity was up to $10000 \mathrm{ug} / \mathrm{l}$. Between-batch precision coefficients of variation for quality control samples $(10,100$, 400 and $1000 \mathrm{ug} / \mathrm{l})$ were $<10 \%$. Recoveries for spiked standards into blank matrix at concentrations of 100 , 400 and $1000 \mu \mathrm{g} / \mathrm{l}$ were $>99 \%$.

Urine albumin and creatinine were measured on a Roche Modular Analytics system (Roche Diagnostics $\mathrm{GmbH}$, Mannheim, Germany). Urine albumin was measured by turbidimetry and urine creatinine was measured by kinetic Jaffe reaction using the standard reagent kits provided by the instrument manufacturer. Their analytical performances were within the manufacturer's specifications.

Urinalysis was performed by Multistix (Siemens urine test strips 10SG, Bayer). Microscopic examination was performed, by examining $60 \mu \mathrm{l}$ of urine in microtitre plates using an inverted microscope, to look for red blood cells, casts and crystals in urine. Quantitative culture of urine was performed on Chromogenic medium (CPS ID3 [Biomerieus] plate using $10 \mu \mathrm{l}$ standard loops incubated aerobically for 18 to $24 \mathrm{hr}$ at $35^{\circ} \mathrm{C}$.

\section{Statistical Analysis}

Data were presented using appropriate descriptive statistics. Comparisons on baseline clinical and biochemical characteristics between those with and without high urinary melamine level (urine melamine/creatinine ratio $>7.1$ $\mu \mathrm{g} / \mathrm{mmol}$ ) were made using Pearson's Chi square test, Fisher's exact test, T-test and Mann-Whitney test, as appropriate. Association between daily milk consumption 
and melamine level was assessed using Mann-Whitney test and Pearson's Chi-square test, depending on the data format of melamine level. Spearman correlation coefficient was used to assess the correlation between urine $\mathrm{ACR}$ and urine melamine/creatinine ratio. All statistical analyses were performed using SPSS 17.0 (SPSS Inc., Chicago, IL). All statistical tests were two-sided and a Pvalue $<0.05$ was considered statistically significant.

\section{Results}

Age of the study cohort ranged from 6 to 20 years with $67 \%$ girls (335 female and 167 male subjects). Table 1 shows the clinical and biochemical characteristics of the 502 school children recruited in this analysis. The spot urine melamine/creatinine ratio of the 502 school children ranged from undetectable to $1467 \mu \mathrm{g} / \mathrm{mmol}$ (median $=0.8)($ Table 1). Of these, 213 school children had undetectable spot urine melamine/creatinine ratio (42\%). Urine albumin ranged from undetectable to $207 \mathrm{mg} /$ mmol. Median urine ACR was $0.70 \mathrm{mg} / \mathrm{mmol}$ (IQR: $0.45-2.01 \mathrm{mg} / \mathrm{mmol}$ ). Age, body weight, body height and body mass index were associated with elevated urinary melamine level (Table 1). There was no significant correlation between urine melamine/creatinine ratio and ACR. There were 25 subjects with missing milk consumption data from the dietary questionnaire. There was no significant association between the milk consumption and urine analysis in 477 subjects with available data (Table 2).

Forty seven subjects (9\%) with high urine melamine level were identified. One subject refused to come back for follow-up study. Median follow-up duration was 23.5 months (interquartile range, IQR: 19.8 - 30.6 months). Table 3 shows the clinical and biochemical characteristics of the 46 subjects ( $28 \%$ boys, mean age $13.9 \pm 2.9$ years) identified with elevated urine melamine level who returned for follow-up evaluation. None of them had any abnormality detected on ultrasound study of the urinary system. None of them recalled any significant urinary tract symptoms or had abnormalities on urinalysis.

\section{Discussion}

To our knowledge, our study is the first to explore the clinical course of subjects identified with elevated urine melamine level from a territory-wide survey. All participants were healthy volunteers without symptoms or known history of consumption of melamine-contaminated products. In agreement with a previous report of children aged 12 years or less known to have consumed milk products contaminated with melamine [2], we did not detect any major adverse renal outcomes in this cohort of older school children with elevated urine melamine level. Since albuminuria is known to be an early marker of renal damage, we investigated the association of urine albumin level with melamine level in subjects with high urine melamine level and did not find any significant association.

In this cohort, young age, low body weight and height, low body mass index were all associated with elevated urinary melamine level. Since young school children tend to have higher milk consumption, it is plausible that age may be the factor linking urinary melamine level and anthropometric parameters although we were

Table 1 Baseline clinical and biochemical characteristics of the study sample $(\mathbf{n}=502)$.

\begin{tabular}{|c|c|c|c|c|}
\hline \multirow[b]{2}{*}{ Characteristics } & \multirow{2}{*}{$\begin{array}{l}\text { All participants } \\
\qquad(n=502)\end{array}$} & \multicolumn{2}{|c|}{$\begin{array}{l}\text { Elevated urinary melamine level (urine melamine/creatinine ratio } \\
\qquad>7.1 \mathrm{ug} / \mathrm{mmol} \text { ) }\end{array}$} & \multirow[b]{2}{*}{ p-value } \\
\hline & & No $(n=455)$ & Yes $(n=47)$ & \\
\hline \multicolumn{5}{|l|}{ Sex ${ }^{\psi}$} \\
\hline Male & $167(33.3 \%)$ & $153(33.6 \%)$ & $14(29.8 \%)$ & $0.595^{\mathrm{a}}$ \\
\hline Female & $335(66.7 \%)$ & $302(66.4 \%)$ & $33(70.2 \%)$ & \\
\hline Age (years) & $13.2(3.0)$ & $13.3(3.0)$ & $12.0(2.8)$ & $0.004^{b}$ \\
\hline Body weight (kg) & $43.6(11.8)$ & $44.1(11.7)$ & $39.3(12.1)$ & $0.008^{b, *}$ \\
\hline Body height $(\mathrm{cm})$ & $152.3(13.6)$ & $152.8(13.4)$ & $147.4(14.6)$ & $0.010^{b, *}$ \\
\hline BMI $\left(\mathrm{kg} / \mathrm{m}^{2}\right)$ & $18.5(3.0)$ & $18.6(3.0)$ & $17.5(2.4)$ & $0.026^{b, *}$ \\
\hline \multicolumn{5}{|l|}{ Weight status ${ }^{\psi}$} \\
\hline Normal & $428(85.3 \%)$ & $384(84.4 \%)$ & $44(93.6 \%)$ & $0.193^{c}$ \\
\hline Overweight & $51(10.2 \%)$ & $48(10.5 \%)$ & $3(6.4 \%)$ & \\
\hline Obesity & $23(4.6 \%)$ & $23(5.1 \%)$ & 0 & \\
\hline${\text { Urine albumin-creatinine ratio }(\mathrm{mg} / \mathrm{mmol})^{\dagger}}^{\dagger}$ & $0.70(0.45-2.01)$ & $0.69(0.44-3.23)$ & $0.70(0.50-1.39)$ & $0.820^{d}$ \\
\hline Urine melamine/creatinine ratio $(\mu \mathrm{g} / \mathrm{mmol})^{\dagger}, \S$ & $0.76(0.00-2.62)$ & $0.52(0.00-1.73)$ & $13.21(9.09-21.55)$ & $<0.001^{\mathrm{d}}$ \\
\hline
\end{tabular}

Data marked with ${ }^{\dagger}$ were presented as medians (interquartile ranges) and with ${ }^{\psi}$ as frequencies (\%), all others were presented as means (standard deviations).

${ }^{a}$ Chi square test; ${ }^{\mathrm{b}}$ T-test; ${ }^{\mathrm{c}}$ Fisher's exact test; ${ }^{\mathrm{d}}$ non-parametric Mann-Whitney test.

$\S$ Undetectable urine melamine level was set to zero.

* There was no statistically significance between the two groups on body weight, body height, BMl and waist circumference after adjusting for age. 
lead to long term adverse renal outcome cannot be addressed by this short-term study of 2 years duration. Second, the sample size was relatively small with only 502 children being studied due to limited funding available to examine all urine aliquots for melamine level. Third, we did not record detailed food diary regarding the potential or known melamine-tainted milk products when urine was sampled in 2007-08.

\section{Conclusions}

Hong Kong Chinese school children with high urine melamine levels appear to have benign clinical course in the short term. Periodic urine sampling for melamine level in a larger population will provide more complete information regarding the impact of prolonged exposure to melamine ingestion. In children and adolescents with persistently high urine melamine level, long term follow up is required to detect any adverse clinical effects.

\begin{abstract}
Acknowledgements
We thank all school personnel, parents and participants for making this study possible. This study was supported by funding from the Food and Health Bureau (Ref number: MI-FU-04) and the Research Grant Committee (ref number: CUHK 4465/06 M).
\end{abstract}

\section{Author details \\ 'Department of Medicine and Therapeutics, The Chinese University of Hong Kong, Prince of Wales Hospital, Shatin, Hong Kong SAR, China. ${ }^{2}$ Li Ka Shing Institute of Health Sciences, The Chinese University of Hong Kong, Prince of Wales Hospital, Shatin, Hong Kong SAR, China. ${ }^{3}$ The Nethersole School of Nursing, The Chinese University of Hong Kong, Shatin, Hong Kong SAR, China. ${ }^{4}$ Department of Chemical Pathology, The Chinese University of Hong Kong, Prince of Wales Hospital, Shatin, Hong Kong SAR, China. ${ }^{5}$ Department of Diagnostic Radiology and Imaging, The Chinese University of Hong Kong, Prince of Wales Hospital, Shatin, Hong Kong SAR, China. ${ }^{6}$ Department of Microbiology, The Chinese University of Hong Kong, Prince of Wales Hospital, Shatin, Hong Kong SAR, China. ${ }^{7}$ School of Public Health and Primary Care, The Chinese University of Hong Kong, Prince of Wales Hospital, Shatin, Hong Kong SAR, China. ${ }^{8}$ Hong Kong Institute of Diabetes and Obesity, The Chinese University of Hong Kong, Prince of Wales Hospital, Shatin, Hong Kong SAR, China.}

\section{Authors' contributions}

APSK prepared the proposal and supervised the study. APSK, KCC, CSH and JCNC interpreted the results, prepared the final manuscript and were responsible for data management and analysis. JTFL advised on data analysis. CSH, CKW, WCWC and JCNC contributed to the conception of the study and revision of the manuscript. CSH, MHMC, CKW and VC supervised the laboratory procedures. EKHL and WCWC provided technical support and supervised the imaging procedures. All authors read and approved the final manuscript.

\section{Competing interests}

The authors declare that they have no competing interests.

Received: 4 January 2011 Accepted: 20 May 2011

Published: 20 May 2011

\section{References}

1. Parry J: China's tainted infant formula sickens nearly 13,000 babies. BMJ 2008, 337:a1802.

2. Lam HS, Ng PC, Chu WCW, Wong W, Chan DFY, Ho SS, Wong KT, Ahuja AT, Li CK: Renal screening in children after exposure to low dose melamine in Hong Kong: cross sectional study. BMJ 2008, 337:a2991.
3. Ho SS, Chu WCW, Wong KT, Li CK, Wong W, Ng PC, Ahuja AT: Ultrasonographic evaluation of melamine-exposed children in Hong Kong. N Engl J Med 2009, 360(11):1156-1157.

4. Lau HY, Wong CS, Ma JK, Kan E, Siu KL: US findings of melamine-related renal disorders in Hong Kong children. Pediatr Radiol 2009, 39(11):1188-1193.

5. Kong APS, Choi KC, Li ACM, Hui SSC, Chan MHM, Wing YK, Ma RCW, Lam CWK, Lau JTF, So WY, Ko GTC, Chan JCN: Association between physical activity and cardiovascular risk in Chinese youth independent of age and pubertal stage. BMC Public Health 2010, 10:303.

6. Guldan GS, Wong SM, Ozaki R, Chan J, Au Yeung M: Validation of the oneminute dietary assessment to assess the dietary behaviors of Hong Kong adolescents. Fourth Annual Conference of the International Society of Behavioral Nutrition and Physical Activity Amsterdam, The Netherlands; 2005, 16-18.

7. Mogensen CE, Vestbo E, Poulsen PL, Christiansen C, Damsgaard EM, Eiskjaer H, Frøland A, Hansen KW, Nielsen S, Pedersen MM: Microalbuminuria and potential confounders. Diabetes Care 1995, 18:572-581.

8. Lam CW, Lan L, Che X, Tam S, Wong SS, Chen Y, Jin J, Tao SH, Tang XM, Yuen KY, Tam PK: Diagnosis and spectrum of melamine-related renal disease: plausible mechanism of stone formation in humans. Clin Chim Acta 2009, 402(1-2):150-155.

9. Parry J: China's tainted milk scandal spreads around world. BMJ 2008, 337:a1890.

10. Xin H, Stone R: Tainted milk scandal. Chinese probe unmasks high-tech adulteration with melamine. Science 2008, 322(5906):1310-1311.

11. Cruywagen CW, van de Vyver WF, Stander MA: Quantification of melamine absorption, distribution to tissues and excretion by sheep. J Anim Sci 2011.

12. Osborne CA, Lulich JP, Ulrich LK, Koehler LA, Albasan H, Sauer L, Schubert G: Melamine and cyanuric Acid-induced crystalluria, uroliths, and nephrotoxicity in dogs and cats. Vet Clin North Am Small Anim Pract 2009, 39(1):1-14

\section{Pre-publication history}

The pre-publication history for this paper can be accessed here: http://www.biomedcentral.com/1471-2458/11/354/prepub

doi:10.1186/1471-2458-11-354

Cite this article as: Kong et al:: Hong Kong Chinese school children with elevated urine melamine levels: A prospective follow up study. BMC Public Health 2011 11:354.

\section{Submit your next manuscript to BioMed Central and take full advantage of:}

- Convenient online submission

- Thorough peer review

- No space constraints or color figure charges

- Immediate publication on acceptance

- Inclusion in PubMed, CAS, Scopus and Google Scholar

- Research which is freely available for redistribution

Submit your manuscript at www.biomedcentral.com/submit
C Biomed Central 